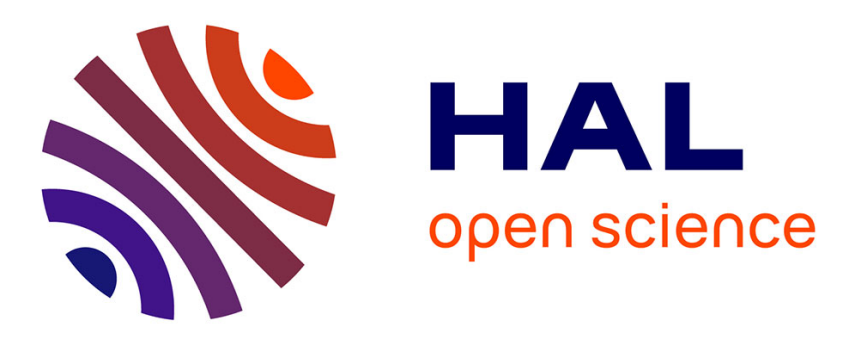

\title{
Thermal Fatigue With Freeze-Thaw Cycles of Polymer Modified Bitumen
}

Bachir Glaoui, Martin van de Ven, Emmanuel Chailleux, Abdelkader Youcefi

\section{To cite this version:}

Bachir Glaoui, Martin van de Ven, Emmanuel Chailleux, Abdelkader Youcefi. Thermal Fatigue With Freeze-Thaw Cycles of Polymer Modified Bitumen. Journal of Applied Sciences, 2011, 11 (6), pp 1012-1018. 10.3923/jas.2011.1012.1018 . hal-00637506

\section{HAL Id: hal-00637506 https://hal.science/hal-00637506}

Submitted on 2 Nov 2011

HAL is a multi-disciplinary open access archive for the deposit and dissemination of scientific research documents, whether they are published or not. The documents may come from teaching and research institutions in France or abroad, or from public or private research centers.
L'archive ouverte pluridisciplinaire HAL, est destinée au dépôt et à la diffusion de documents scientifiques de niveau recherche, publiés ou non, émanant des établissements d'enseignement et de recherche français ou étrangers, des laboratoires publics ou privés. 
Journal of Applied Sciences 11 (6): 1012-1018, 2011

ISSN 1812-5654 / DOI: 10.3923/jas.2011.1012.1018

(C) 2011 Asian Network for Scientific Information

\title{
Thermal Fatigue with Freeze-thaw Cycles of Polymer Modified Bitumen
}

\author{
${ }^{1}$ Bachir Glaoui, ${ }^{2}$ Martin van de Ven, ${ }^{1} \mathrm{M}$ 'hamed Merbouh, ${ }^{3} \mathrm{Emmanuel}$ Chailleux and ${ }^{4}$ Abdelkader Youcefi \\ ${ }^{1}$ Reliability Laboratory of Materials and Sructures in Saharan Regions (FIMAS), \\ Bechar University B.P. 417, Bechar, 08000, Algeria \\ ${ }^{2}$ Laboratory of Road and Railway Engineering-TU Delft-P.O. Box 50482600 GA Delft, Netherlands \\ ${ }^{3}$ Central Laboratory of Bridges and Pavements, Road of Bouaye-BP 412944341 Bouguenais Cedex France \\ ${ }^{4}$ Laboratory of Rheology-USTO- BP 1505 El Mnaouer-Oran- Algerie, Algeria
}

\begin{abstract}
This research contributes to characterize the EVA polymer modified bitumen, which was subjected to thermal fatigue. The aim of this work was to determine the rheological components and their evolutions under thermal fatigue with freezing - thawing cycles. To represent thermal fatigue phenomenon of polymer modified bitumen in laboratory, both freezer and controlled temperature room were used to produce the real cycles of freeze-thaw of winter season. The results suggest that thermal fatigue is more complicated on rheological behavior of polymer modified bitumen. It is shown that thermal fatigue influenced thermal cracking, fatigue cracking and permanent deformation resistance. It is concluded that thermal fatigue due to thermal cycling, is a big problem to accelerate the degradation of pavement.
\end{abstract}

Key words: Polymer modified bitumen, rheology, thermal fatigue, freeze-thaw

\section{INTRODUCTION}

Various factors affect the deformation behavior and performance of asphalt concrete, including time, temperature, stress state, mode of loading, aging and moisture (Kim, 2009).

The temperature has a great influence on the performance of pavements. Thermal cracking is one mechanism that accelerates the degradation of asphalt concrete (Anderson et al., 2007). Thermal cracking is a serious problem that results in both structural and functional problems in asphalt concrete pavements (Yen et al., 2006).

The asphalt concrete pavements are constantly subjected to temperature fluctuations and the physical properties of asphalt concrete are highly temperature dependent. This thermal loading results in the development of thermal stresses in the pavements (Al-Qadi et al., 2005). Thermal fatigue is among distresses developed in flexible pavements due to temperature variation. Tensile stresses tend to increase in the pavement as the temperature decreases, and at very low temperatures cracking occurs once the developed stresses exceed the tensile strength (Sebaaly et al., 2002; $\mathrm{Xu}$ and Solaimanian, 2008).

A lot of researches has been conducted to study the complexity of thermal fatigue phenomenon. Until now, a standard test method is not available for evaluating mixture and binder resistances to thermal fatigue. The bitumen binder is the first factor that participates in the degradation of asphalt concrete.

The present study focuses on thermal fatigue of polymer modified bitumen binder. In this research, the objective was to determine the evolution of rheological components of EVA polymer modified bitumen under effects of the thermal fatigue with freezing-thawing cycles.

The flexible pavements are subjected to deterioration from seasonal freezing and thawing (Karen et al., 2005). In the winter, the pavement structures modulus increases because of ice segregation in the unbound base or subgrade and because of the influence of temperature on the viscosity of the asphalt concrete. During spring thaw, the pavement foundation can become saturated with water from the thawing ice lenses, thus reducing the structural adequacy of the base or subgrade. With a weakened structure, the pavement cannot support the load it was designed for; therefore, one can expect most of the damage to a pavement to occur during the spring thaw. Damage to the pavement structure will reveal itself on the surface in the form of fatigue cracking and rutting (Janoo and Berg, 1990).

Bituminous concrete pavements are known to be susceptible to thermal distress when subjected to changes in ambient temperatures. Several researchers

Corresponding Author: Bachir Glaoui, Reliability Laboratory of Materials and Structures in Regions (FIMAS), Bechar University B.P. 417, Bechar, 08000, Algeria 
have proposed that thermal cracking can be divided into two modes of distress: (a) low temperature cracking and (b) thermal fatigue cracking (Vinson et al., 1989; Lytton et al., 1983).

Although previous research efforts have improved the understanding of the interaction between asphalt pavements and the environment, at the present there is not universal acceptance of thermal fatigue as a distress mechanism causing thermal cracking (Epps, 1999). In examining the hypothesis of this mechanism of failure, thermal fatigue must be isolated from low temperature cracking. As a result, only those approaches that separate the effects of the two different forms of thermal cracking are recommended to explore the phenomenon of thermal fatigue. An advantage of direct measurement of mixture response to thermal cycling is the absence of necessary assumption of material behavior required in mechanismsbased approaches (Epps, 1999). Previous laboratory testing programs employing direct measurement of mixture response have produced mixed results. The Federal Highway Administration report, (1994) indicated that thermal fatigue is not a viable distress mode in the absence of environmental aging (Federal Highway Administration, 1994). But, Sugarawa and Moriyoshi (1984) suggested that mixtures do have a finite capacity for thermal fluctuations with low temperatures greater than but close to the mixture fracture temperature (Sugarawa and Moriyoshi, 1984).

Thermal fatigue failure is hypothesized to result from repeated tensile stresses induced by temperature fluctuations in the pavement as temperature decreases and contraction is restrained. Aging of asphalt-aggregate mixture contributes to the level of stress induced. Both rapid short-term aging during plant mixing and construction and slower long-term aging in the field stiffen the mixture and increase the stress induced on cooling. When the effect of thermal cycling exceeds the mixture fatigue resistance, transverse cracks result from the maximum stress in the longitudinal direction of the pavement (Epps, 1999).

\section{MATERIALS AND METHODS}

This research was conducted from October 2007 to March 2010 in multiple places: in Algeria (Bechar university), France (LCPC) and Netherlands (laboratory of Road and Railway engineering-TU Delft).

Materials: The bitumen binder used in this study is 40/50penetration grade. Usually it is used in aerodrome and road pavements in hot regions in Algeria.
The polymer was used as a modifying agent; thermoplastic material of Ethylene Vinyl Acetate (EVA) copolymer with $18 \%$ Vinyl Acetate contents.

The polymer modified bitumen was manufactured at the laboratory of LCPC (Central laboratory of bridges and pavements (France) by mixing during $2 \mathrm{~h}$ the bitumen with $5 \%$ of polymer under moderate shear stirring (about 1000 tours $/ \mathrm{min}$ ) at $160^{\circ} \mathrm{C}$ temperature.

Test program: This study focuses on the fundamental rheological properties of two binders:

- The unaged polymer modified bitumen is: $40 / 50$ bitumen modified with $5 \%$ of EVA polymer

- The aged polymer modified bitumen with thermal fatigue; which is resulted from the same origin of unaged polymer modified bitumen binder

The experimental method of thermal fatigue in this study is as; Firstly, using a freezer to regulate the low temperature wanted and controlled temperature room. Then putting the polymer modified bitumen inside the freezer. After that getting out the modified bitumen and putting inside a controlled temperature room to produce the thaw of this binder. The repeating thermal cycles on modified binder leads to produce a phenomenon of thermal fatigue.

The aged polymer modified binder was submitted to thermal fatigue with freezing-thawing cycles. The temperatures of the study tests were: $-10^{\circ} \mathrm{C}$ for freezing and $25^{\circ} \mathrm{C}$ for thawing. The specimen was exposed to 100 cycles of thermal loading. Figure 1 illustrates one cycle of temperatures in $24 \mathrm{~h}$. As shown in Fig. 1, the duration of freezing and thawing was the same $12 \mathrm{~h}$. For each applied thermal solicitation, it is assured $10 \mathrm{~h}$ constant duration during the test. The fundamental characterization was done using the Dynamic Shear Rheometer (DSR) and Bending Beam Rheometer (BBR).

The Dynamic Shear Rheometer (DSR) was used to perform frequency sweeps on aged and un-aged binders at different temperatures $-5,0,20,30,40,50$ and $60^{\circ} \mathrm{C}$.

Measurements were taken at different temperatures. The $8 \mathrm{~mm}$ spindle was used for measurements at the temperature $-5,0,20$ and $30^{\circ} \mathrm{C}$. The $25 \mathrm{~mm}$ spindle was used for the temperatures 40,50 and $60^{\circ} \mathrm{C}$. The gap width of 2 and $1 \mathrm{~mm}$ was used for the small spindle $(8 \mathrm{~mm})$ and the large spindle $(25 \mathrm{~mm})$, respectively.

The Bending Beam Rheometer (BBR) is a simple specification tool that measures asphalt stiffness at low ternperatures under controlled loading conditions. The load is used to simulate the stresses that gradually 


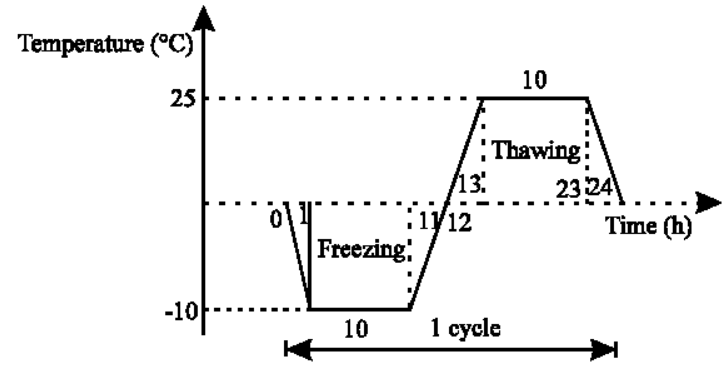

Fig. 1: One cycle of thermal loading

build up in pavement when temperature drops (Federal Highway Administration, 1994). Two parameters: the flexural creep stiffness and $m$-value, are obtained with the BBR. The flexural creep stiffness represents the resistance of asphalt for constant loading and $\mathrm{m}$-value does the change of asphalt creep stiffness (Lee, 1997).

In this study, the Bending Beam Rheometer (BBR) was used to measure the creep stiffness and $m$-value, which were taken at low temperature- $20^{\circ} \mathrm{C}$.

\section{RESULTS AND DISCUSSION}

Master curves: Figure 2 represents the master curves of complex modulus and phase angle of unaged polymer modified bitumen. At low temperatures or high frequencies, the polymer modified bitumen tends to a big complex modulus value and a small phase angle value. The big value of complex modulus reflects the rigidity of the modified binder. The small value of phase angle represents the elastic nature of the binder at these frequencies. The temperatures -5 and $0^{\circ} \mathrm{C}$ have the same behavior, when the frequency increases, the complex modulus increases and phase angle decreases.

As the frequency decreases or as the temperature increases, the complex modulus decreases while the phase angle increases. The first reflects a decrease in resistance to deformation (softening) while the second reflects decrease in elasticity or the ability to store energy (Bahia, 2009). The temperatures 20 and $30^{\circ} \mathrm{C}$ have the same behavior. The frequency increases, the complex modulus increases and also phase angle increases. This result is in contraction to the results of Bahia (2009) because the behavior of modified bitumen is changed due to the type of polymer, which is EVA (Ethylene Vinyl Acetate). But it is in support to the research of Lu et al. (1999). In this case, the EVA polymer modified binder has recovery of elasticity.

Rutting can occur especially in regions where hot climates can lead to a reduction in binder viscosity (D'Angelo, 2002). At high temperatures 40,50 and $60^{\circ} \mathrm{C}$, as temperature increases, the complex modulus decreases continuously, and phase angle increases to approach value of $55^{\circ}$ that reflects the elasticity behavior or ability to store energy. At high pavement temperatures, a low phase angle is desirable since this reduces permanent deformation (Maccarrone, 1995). The EVA polymer displays a great role to reduce thermal susceptibility (Brule and Maze, 1995). So, the EVA polymer-modified bitumen has more elasticity, which is good for rutting performance. This result is in support to a lot of researches (D'Angelo, 2002; Maccarrone, 1995; Brule and Maze, 1995).

Figure 3 represents the master curves of complex modulus and phase angle of thermal fatigue with freezingthawing cycles of polymer modified bitumen. At low temperatures or high frequencies, the aged polymer modified bitumen has a high stiffness and a low phase angle. The temperature -5 and $0^{\circ} \mathrm{C}$ have the same behavior. The frequency increases, the complex modulus increases and phase angle decreases.

At intermediate temperatures, as the temperature increases, the complex modulus decreases continuously while the phase angle increases continuously. For the temperatures 20 and $30^{\circ} \mathrm{C}$, the complex modulus increases and also phase's angle increases with increasing of frequency.

At high temperatures or low frequencies, as the temperature increases, the complex modulus decreases and the phase angle increase to approach a value of approximately $58^{\circ}$. For temperatures 40 and $50^{\circ} \mathrm{C}$, the complex modulus increases and phases angle decreases with increasing of frequency. However, at $60^{\circ} \mathrm{C}$, when the frequency increases, the phase angle remains constant while the complex modulus increases continuously.

Effects of thermal fatigue: Figure 4 shows black curves of aged polymer modified bitumen submitted to thermal fatigue with freeze-thaw cycles, and unaged polymer modified bitumen. The aging participates in thermal fatigue phenomenon. This factor changes the binder behaviour by increasing the complex modulus and decreasing phase angle (Bahia, 2009). The slope rate of aged polymer modified bitumen is decreased for each temperature, i.e., a little variation in the phase angle. The effects of thermal fatigue on modified binder reduce the performance and the durability of pavements. At low temperatures $\left(-5\right.$ and $\left.0^{\circ} \mathrm{C}\right)$, a little change is observed a slight increase in the complex modulus and slight decrease in the phase angle. These changes are not favourable since it makes the binders stiffer and more elastic Bahia (2009). So, thermal fatigue leads the modified binder to behave unfavourably concerning thermal cracking. 


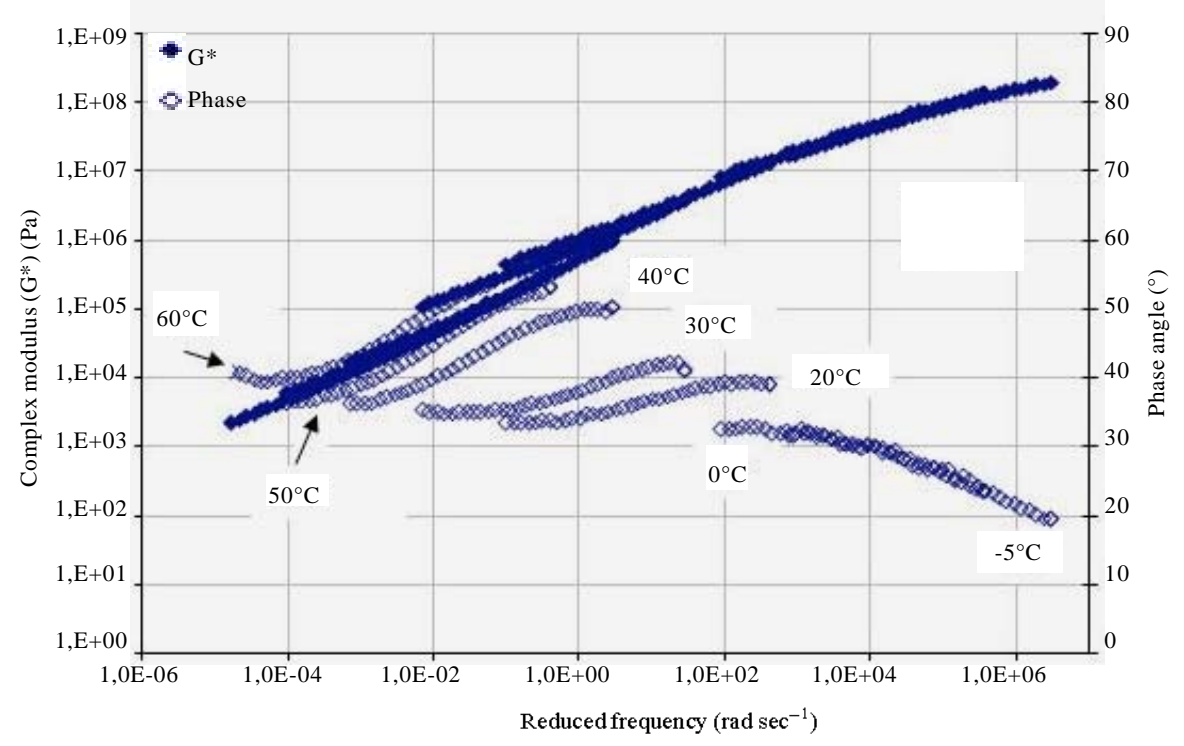

Fig. 2: Master curves of complex modulus and phase angle of unaged polymer modified bitumen at reference temperature $25^{\circ} \mathrm{C}$

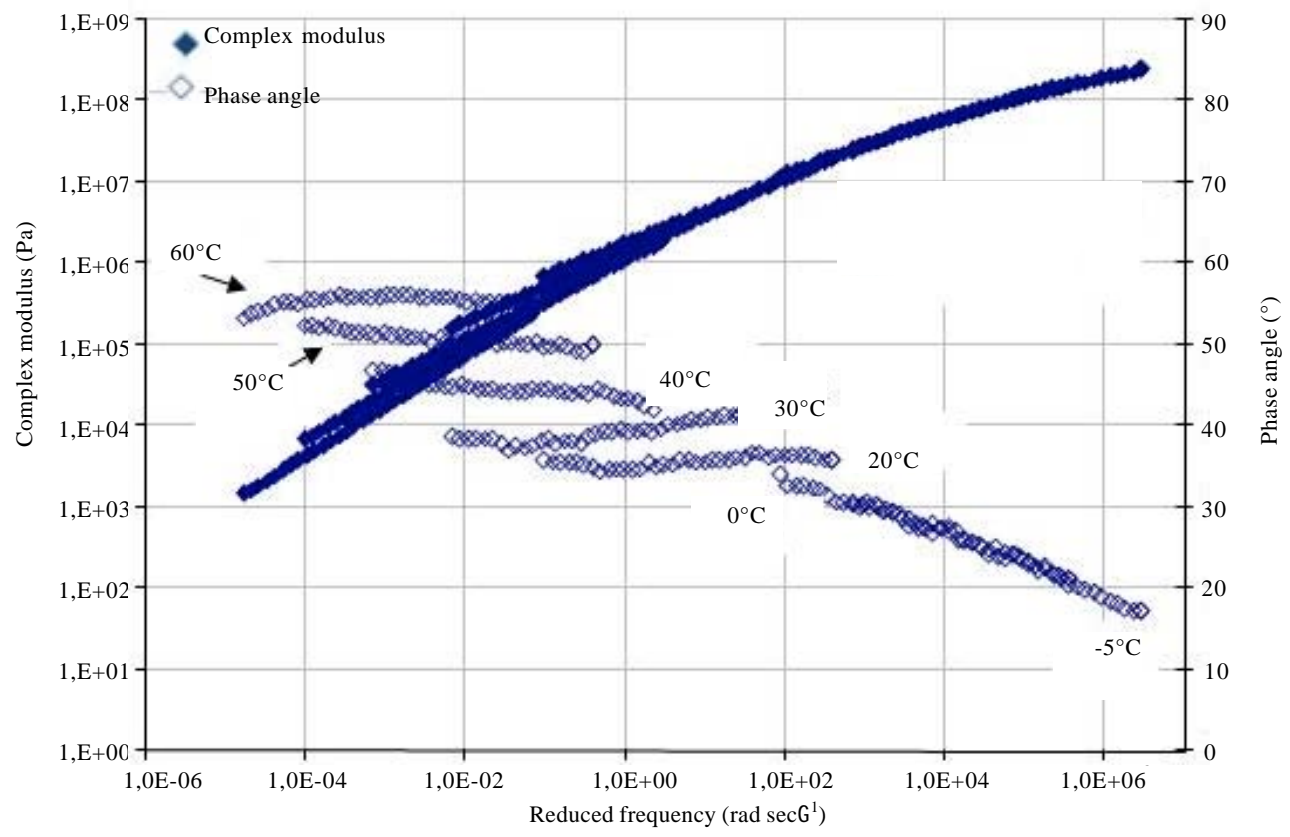

Fig. 3: Master curves of complex modulus and phase angle of aged polymer modified bitumen with reeze - thaw cycles at reference temperature $25^{\circ} \mathrm{C}$

At intermediate temperatures $\left(20\right.$ and $\left.30^{\circ} \mathrm{C}\right)$, the rate of variation of the phase angle is smaller than virgin binder. There is a decrease in the curve slope of aged polymer modified bitumen. Increasing of the complex modulus and decreasing in variation of phase angle appears the changes. In this case, the increasing in the 


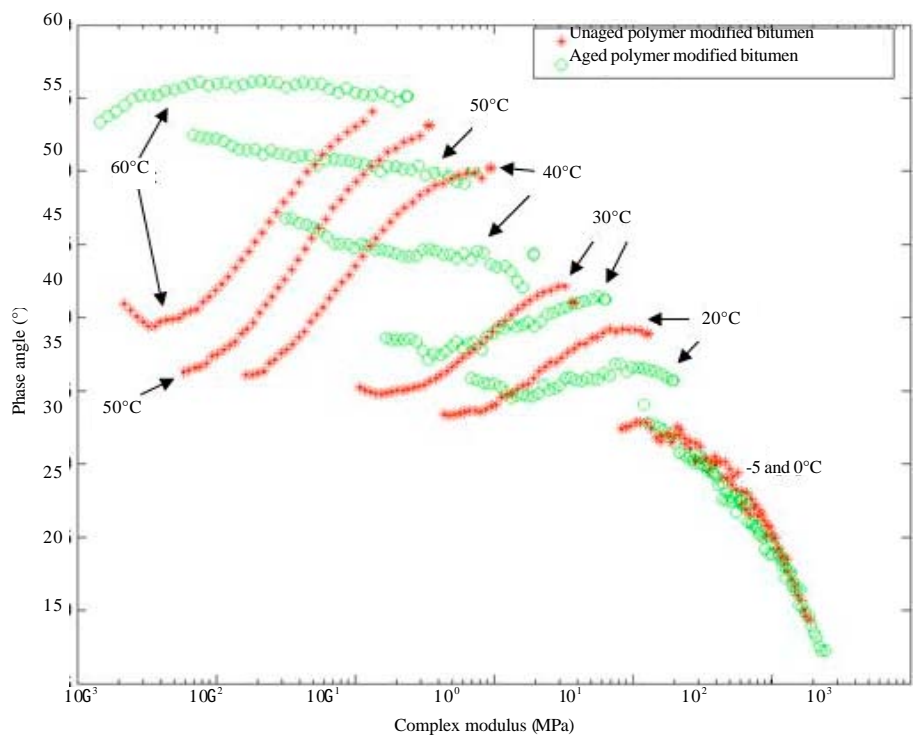

Fig. 4: Comparison between unaged and aged polymer modified bitumen binders

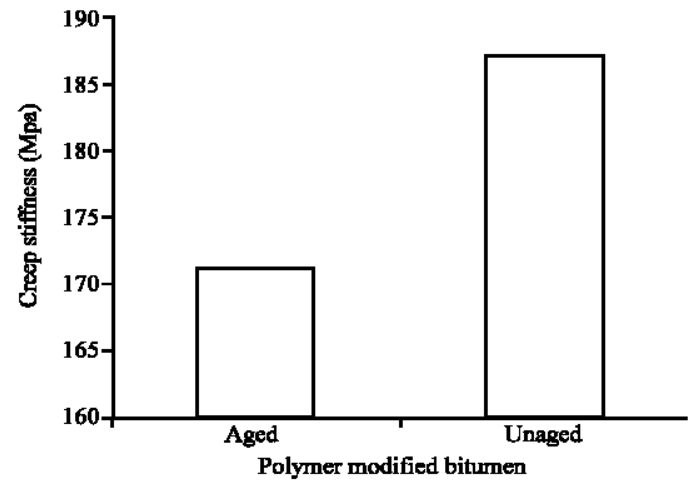

Fig. 5: Creep stiffness of aged and unaged polymer modified bitumen

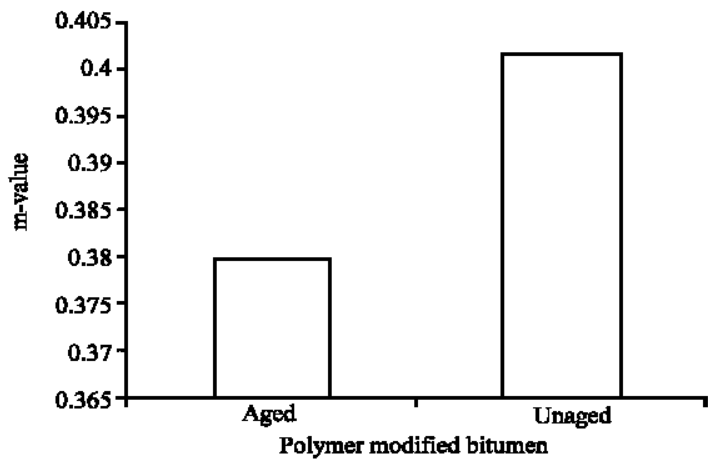

Fig. 6: M-value of aged and unaged polymer modified bitumen complex modulus is not favourable for fatigue cracking, especially for thin pavements (Bahia, 2009).

At high temperatures $\left(40\right.$ and $\left.50^{\circ} \mathrm{C}\right)$, the direction of the curve slopes of aged polymer modified bitumen is changed. The phase angle decreases when the complex modulus increases. This indicates an increase in rigidity and in elasticity, which results in better resistance to permanent deformation (Bahia, 2009). In this case, the EVA polymer reduces the thermal susceptibility (Brule and Maze, 1995) which means a better behaviour concerning the permanent deformation resistance. However, at $60^{\circ} \mathrm{C}$, the phase angle is observed to be higher for the aged modified bitumen and it remain constant during this temperature. Thermal fatigue with freezing - thawing cycles makes polymer-modified bitumen softer and this change is not favourable for permanent deformation resistance.

These results are in support to the studies of Bahia (2009) and Brule and Maze (1995).

Stiffness and m-value: From Fig. 5, the creep stiffness at $60 \mathrm{sec}$ of origin polymer modified bitumen is higher than aged polymer modified bitumen. By the recommendation of SHRP, the specific maximum creep stiffness value at $60 \mathrm{sec}$ is $300 \mathrm{Mpa}$ (Lee, 1997). The results of the two binders are within the limited value.

The obtained m-values are shown in Fig. 6. The $\mathrm{m}$-value of origin polymer modified bitumen is higher than aged polymer modified bitumen, which (Lee, 1997) 
represents the viscosity of origin binder is higher than aged binder with freeze-thaw cycles. Considering the recommended minimum m-value, 0.3 by SHRP, the test results are within the limited (Lee, 1997).

From these results of creep stiffness and m-value, it appears that thermal fatigue with freeze-thaw cycles weaken the quality of polymer modified bitumen. So, the modified binder becomes more deformable when it submitted to freezing-thawing cycles. In cold regions, the bituminous mixes are exhibited, under effect of thermal fatigue with freeze-thaw cycles, to quick degradations.

Many previous researches have been done on thermal fatigue, which explain the problem of this phenomenon on cracking of pavements. From results of this study, it is found that thermal fatigue is a big distress developed in flexible pavements.

\section{CONCLUSION}

The results of this study indicate that thermal fatigue was changed the rheological behavior of polymer modified bitumen. At low temperatures, complex modulus was slightly increased and phase angle was slightly decreased, which are not favorable for thermal cracking. Also from results of the lower values of creep stiffness and $m$-value, which indicate that the modified bitumen becomes more deformable. Within intermediate temperatures, increasing of complex modulus and decreasing in variation of phase angle appears the changes. These changes are not good for fatigue cracking. At high temperatures 40 and $50^{\circ} \mathrm{C}$, there is a decreasing of phase angle and an increasing of complex modulus. In this case, the polymer-modified bitumen has an increase in rigidity and in elasticity, which results a better behavior in front of permanent deformation resistance. But, at $60^{\circ} \mathrm{C}$, the higher of phase angle was not favorable for permanent deformation resistance. Thermal fatigue with freeze-thaw cycles makes the modified binder softer and more deformable.

The pavement performance is affected by thermal fatigue (influencing thermal cracking, fatigue cracking and permanent deformation resistance).

Further research is needed to increase the level of thermal loading (over than 100 cycles) and change the temperatures of cycles that represent the real seasons temperatures.

\section{ACKNOWLEDGMENTS}

The author wishes to express his gratitude to $\mathrm{Mr}$ Abdol Miradi manager of laboratories of Technology University of Delft (Netherlands), who allows doing experimental tests, and Professor Martin van de Ven for his valuable comments and guidance in laboratory of Road and Railway engineering (TU Delft). Also thanks to Milliyon Waldekidan for his assistance. The writer is also grateful to Professor Imad Al-qadi (Illinoise university- USA) and Dr. Emmanuel Chailleux (LCPC- France) for their comments and assistance.

\section{REFERENCES}

Al-Qadi, I.L., M. Marwa and M.A. Elseifi, 2005. Field and theorical evaluation of thermal fatigue cracking in flexible pavements. J. Trans. Res. Record, 1919: 87-95.

Anderson, D.A., L. Lapalu, M.O. Marasteanu, Y.M.L. Hir, J.P. Planche and D. Martin, 2007. Low-temperature thermal cracking of asphalt binders as ranked by strength and fracture properties. Trans. Res. Record: J. Trans. Res. Board, 1766: 1-6.

Bahia, H.U., 2009. Modeling of Asphalt Binder Rheology and its Application to Modified binders, Modeling of Asphalt Concrete. ASCE Press, New York.

Brule, B. and M. Maze, 1995. Application of SHRP binder tests to the characterization of polymer modified bitumens. J. Assoc. Asphalt Paving Technol., 64: $367-392$.

D'Angelo, J.D., 2002. Superpave binder specifications and their performance relationship to modified binders. Proceedings of Canadian Technical Asphalt Association, November 2002, Canada, pp: 91-103.

Epps, A.L., 1999. An approach to examine thermal fatigue in asphalt concrete. J. Asphalt Paving Technol., 68: 319-384.

Federal Highway Administration, 1994. Background of SUPERPAVE Asphalt Binder Test Methods. FHA, Washington, D.C..

Janoo, V.C. andR.L. Berg, 1990. Predicting the behavior of asphalt concrete pavements in seasonal frost areas using nondestructive techniques. Defense Technical Information Center. http:/oai.dtic.mil /oai /oai?verb $=$ getRecord\&metadataPrefix $=$ html\&identif ier $=$ ADA 231292

Karen, S.H., J.P. Olson, S.P. Farrington and J. Lens, 2005. Improved Performance of Unpaved Roads During Spring Thaw. Engineer Research and Development Center, Cold Regions Research and Engineering Laboratory, United State.

Kim, Y.R., 2009. Modeling of Asphalt Concrete: Modeling of Asphalt Concrete. ASCE Press, New York.

Lee, K., 1997. The determination of the flexural creep stiffness of asphalt binder using bending beam rheometer. KSCE J. Civil Eng., 1: 49-57. 
Lu, X., U. Isacsson and J. Ekblad, 1999. Rheological properties of SEBS, EVA and EBA polymer modified bitumens. J. Mater. Struct., 32: 131-139.

Lytton, R.L., U. Shanmugham and B.D. Garret, 1983. Design of asphalt pavements for thermal fatigue cracking. http://openlibrary.org/books /OL3001909M/Design_of_asphalt_pavements_for_ thermal_fatigue_cracking

Maccarrone, S., 1995. Properties of polymer modified binders and relationship to mix and pavement performance. J. Assoc. Asphalt Paving Technol., 64: 209-240.

Sebaaly, P.E., A. Lake and J. Epps, 2002. Evaluation of low-temperature properties of HMA mixtures. J. Trans. Eng., 128: 578-586.

Sugarawa, T. and A. Moriyoshi, 1984. Thermal fracture of bituminous mixtures. Proceeding of the Paving in Cold Area Mini-Workshop, Oct. 15-19, Japan, pp: 291-320.
Vinson, T., V. Janoo and R. Hass, 1989. Summary Report on Low Temperature and Thermal Fatigue Cracking. TRB, National Reseach Council, Washington, D.C..

$\mathrm{Xu}, \mathrm{Q}$. and M. Solaimanian, 2008. Measurement and evaluation of asphalt concrete thermal expansion and contraction. J. Test. Eval., 36: 1-10.

Yen, H., G.R. Chihab and S.M. Stoffels, 2006. A Case Study: Assessing the Sensitivity of the Coefficient of Thermal Contraction of AC Mixtures on Thermal Crack Prediction. In: Asphalt Concrete: Simulation, Modeling and Experimental Characterization, Masad, E., V.P. Panoskaltsis and L. Wang (Eds.). ASCE Press, USA. 